\title{
A ATIVIDADE DE INTELIGÊNCIA E SUA ATUAÇÃO NO ÂMBITO DAS RELAÇÕES INTERNACIONAIS
}

Wellington da Costa Lange ${ }^{*}$

\section{Resumo}

$\mathrm{Na}$ arena de interesses das relações internacionais, os Estados procuram obter o conhecimento, elemento gerador de desenvolvimento e revestido de importância estratégica. O desenvolvimento alcançado por qualquer país atrai a atenção de outros, que, em busca de vantagens competitivas, utilizam qualquer artifício para acessar, mesmo que de modo não autorizado, as informações estratégicas mantidas sob a proteção do sigilo, alvo de ações de espionagem. Para manter tais informações salvaguardadas, os Estados contam com serviços de Inteligência, os quais têm a função de identificar ameaças e oportunidades no conflituoso cenário internacional.

Palavras-chave: Relações internacionais. Inteligência. Conhecimento estratégico.

\section{$1 \mathrm{~A}$ atividade de inteligência}

Desenvolve-se, na arena internacional, onde se digladiam os interesses dos países que dela participam, uma guerra silenciosa, travada diariamente, sem a mínima possibilidade de trégua ou hasteamento de bandeiras brancas. Nela, a busca pela informação que será base de decisão fundamentada, para que objetivos nacionais sejam satisfeitos, desconhece pudores e outras questões éticas. Logo, o Estado que desejar prevalecer deve ter bem sedimentado, em sua estrutura, um órgão que desenvolva a atividade

\footnotetext{
* Bacharel em Relações Internacionais pelo Centro Universitário de Brasília
} 
de Inteligência, responsável por análises fundamentadas e realistas de possíveis cenários, para poder fazer valer sua vontade.

A atividade de Inteligência compreende um processo e uma combinação de disciplinas específicas e fontes, que tornam viáveis análises de perspectivas relativas a assuntos internacionais e nacionais, fundamentalmente no que diz respeito à coleta e busca do conhecimento, no seu emprego, principalmente, em proveito do Estado.

Um bom conceito a respeito de Inteligência pode ser expresso como sendo essa atividade um processo de: identificação das necessidades de informações; coleta (e busca, quando realizada em proveito do Estado) de dados de interesse; análise, integração, disseminação, utilização e validação (ou reorientação) do esforço. Isso ocorre mediante o uso de metodologia peculiar, com vistas ao assessoramento do planejamento e da decisão nos Estados ou nas organizações e à proteção da informação crítica ou sensível. Paralelo a isso, o objetivo principal da atividade de Inteligência é promover a otimização das ações de grupos decisores, considerando-se as metas visualizadas.

Os adversários da época da Guerra Fria usavam sistemas hierárquicos familiares, com métodos de comando e controle previsíveis. Com a modificação de vários elementos daquela estrutura, como a revolução na área de telecomunicações e o próprio ocaso do Império Soviético, os cenários, então previstos, sofreram profundas alterações.

$\mathrm{O}$ redirecionamento de interesses e a disputa por espaços e influência entre importantes países do mundo causaram forte impacto na atividade de Inteligência. De acordo com um relatório elaborado pelo Parlamento Europeu, "após o término da Guerra Fria, os serviços de 
Inteligência reconheceram uma necessidade de transformação em suas atividades"1.

Mars gravior sub pace latet ${ }^{2}$ : a pior guerra esconde-se sob a paz. Na conjuntura internacional atual, a iminência de um conflito armado em larga escala dissipou-se. As ameaças que agora pairam sobre os Estados são mais dissimuladas e, conseqüentemente, mais imprevisíveis. Portanto, com o intuito de preservar seus interesses, evitar ou minimizar o efeito de elementos nocivos e alcançar os objetivos estabelecidos por suas políticas, é imprescindível que os países contem com serviços de Inteligência, pois, como bem disse Vladimir Yefimovich Semichastny, diretor do serviço de Inteligência soviético, o Komitat Gosudarstvennoy Bezopasnostii (KGB), de 1961 a 1967, "you cannot protect a State with smiles and handshakes”3. Sherman Kent explica que "as informações da grande estratégia e da Segurança Nacional não são produzidas espontaneamente em função do processo normal de governo; são elaboradas por meio de um mecanismo complexo e de um intenso esforço dirigido nesse sentido" ${ }^{4}$. Por isso, é imprescindível a existência de um órgão voltado para a atividade de Inteligência na estrutura de um Estado.

Os desafios da atividade de Inteligência crescem exponencialmente em variedade, volume e velocidade. Ameaças transnacionais como terrorismo, crime organizado e apropriação indevida de conhecimento, dentre vários outros, passaram a fazer parte da agenda de todos os órgãos de Inteligência.

De um modo genérico, o termo "Inteligência" abrange tanto o aspecto de obtenção quanto o de proteção ao conhecimento. As atividades 
que têm como finalidade esses aspectos, embora correlatas, recebem denominações específicas diferentes: a que trata da obtenção de conhecimento é designada Inteligência, e a que preza pela proteção ao conhecimento é conhecida como Contra-Inteligência.

A atividade de Inteligência de Estado pode ser apresentada como aquela que objetiva "a obtenção, análise e disseminação de conhecimentos dentro e fora do território nacional sobre fatos e situações de imediata ou potencial influência sobre o processo decisório e a ação governamental e sobre a salvaguarda e a segurança da sociedade e do Estado" 5 .

Esse conceito, apresentado dentro da regulamentação jurídica brasileira pela Lei $n^{\circ} 9.883$, artigo $1^{\circ}, \S 2^{\circ}$, aplica-se, fundamentalmente, em um contexto de ação estatal. Quando interpretado pela esfera privada, o conceito é basicamente o mesmo, somente alterando-se os atores envolvidos, que podem passar, por exemplo, de países para empresas, mas sem perder a essência de conhecimento acerca de potencialidades e ameaças inerentes aos possíveis cenários.

A Inteligência também tem a função de demandar análises a fim de possibilitar a identificação tanto de oportunidades quanto de óbices referentes à implementação das políticas nacionais. Os objetivos nacionais geram efeitos em todos os níveis da sociedade, disso decorrendo a necessidade de se manter um constante fluxo de informações acuradas que podem influenciar em sua formulação e consecução.

Como oportunidades e ameaças desaparecem tão repentinamente quanto surgem, devido à mutabilidade dos cenários, fica patente a característica perene da atividade de Inteligência. Trata-se de uma atividade que, em razão de sua especialização e das situações nas quais ela 
atua, deve ser, permanentemente, desempenhada por profissionais treinados e cônscios da sua condição como integrantes de um vetor de expressão do poder nacional e, portanto, detentores de uma imensa responsabilidade e compromisso para com o Estado e a sociedade.

É válido esclarecer que a atividade de Inteligência não é exercida somente por instituições civis, sendo essencial destacar a valiosa contribuição de instituições militares para tal atividade. A Inteligência Militar é uma atividade técnico-militar especializada, permanentemente exercida, com o objetivo de produzir conhecimentos de interesse do Comandante de qualquer nível hierárquico e de proteger conhecimentos sensíveis, instalações e pessoal das Forças Armadas contra ações realizadas ou patrocinadas pelos serviços de Inteligência oponentes e/ou adversos.

De acordo com o General-de-Divisão Raymundo Nonato de Cerqueira Filho:

A Inteligência militar, exercida no planejamento de operações, tem por objetivo a produção de conhecimentos sobre o inimigo, por meio de um estudo detalhado de sua ordem de batalha, estrutura de comando, doutrina de emprego, métodos de combate, armamentos, equipamentos e outros fatores necessários à determinação das peculiaridades, deficiências, possibilidades e limitações. ${ }^{6}$

Na concepção de uma estratégia de defesa nacional, é fundamental a participação das forças militares na atividade de Inteligência, integradas com os outros órgãos de um sistema de Inteligência.

A sociedade brasileira desconhece as questões de defesa e de política externa, muitas vezes distante do dia-a-dia do homem comum. É difícil mostrar à população brasileira, que não conhece guerra há mais 
de 130 anos, que a inexistência hoje do inimigo não significa que ele não irá se apresentar no futuro e que o poder militar é necessário. O que todos queremos Governo, partidos políticos e sociedade - é um Brasil desenvolvido e forte, com presença internacional ativa e estatura estratégica compatível com seus índices nacionais. Um dos componentes fundamentais da capacitação nacional de um país é o poder militar, pois não pode haver desenvolvimento sem estabilidade nem estabilidade sem segurança.

Essas palavras, ditas pelo então Ministro da Defesa, Dr. Geraldo Quintão, em Audiência Pública perante a Comissão de Relação Exteriores e de Defesa Nacional, em 05 de setembro de 2001 ${ }^{7}$, destacam bem a imprescindibilidade da segurança para a estabilidade e para o desenvolvimento do Brasil, e a manutenção desses elementos é a missão tanto da atividade militar quanto da atividade de Inteligência.

É patente uma atuação conjunta da Inteligência, da diplomacia e dos militares para a manutenção dos objetivos nacionais. A contribuição da área diplomática abrange descrição de fatos e de situações sobre países hospedeiros, informações sobre questões de interesse maior para o Estado e adoção de medidas de proteção aos assuntos sigilosos.

A área militar contribui ao obter e avaliar informações sobre forças oponentes, condições dos combates ou áreas específicas ${ }^{8}$, desinformando adversários, e, assim como a atividade diplomática, ao proceder à proteção de assuntos sigilosos e de informações sensíveis.

Vale ressaltar que as atividades de Inteligência e diplomática sempre coexistiram harmoniosamente na defesa dos interesses do Estado brasileiro, de forma interdependente e inter-relacionada, cabendo à primeira desempenhar ações no universo velado, e à segunda agir no ambiente transparente das relações internacionais, permitindo atingir o domínio mais abrangente possível dos conhecimentos necessários 
para a tomada de decisões pelos dirigentes da política nacional. ${ }^{9}$

A matéria-prima da Inteligência são as informações, que podem abranger aspectos amplos e gerais, e sua necessidade avulta quando se trata de obter conhecimentos que, por sua natureza, devam ser pesquisados e produzidos com o objetivo de serem utilizados para bem fundamentar decisões nos mais altos escalões governamentais ${ }^{10}$.

"Dificilmente uma decisão poderá ser melhor do que as informações em que se baseou" ${ }^{\text {"11 }}$, isso porque estas irão balizar as ações daquela. Logo, a informação, para o processo de tomada de decisão, é um conhecimento indispensável ${ }^{12}$. Sua importância é ainda maior quando se trata de questões relativas à segurança do Estado e da preservação de sua soberania. Somente com informações acerca de riscos e ameaças, os grupos decisores estarão aptos a definir o melhor modo de se lidar com determinada situação.

Cabe ainda citar Sun Tzu, que, em seu livro "A Arte da Guerra", escreve: "Se conhecermos o inimigo e a nós mesmos, não precisamos temer o resultado de uma centena de combates. Se nos conhecemos, mas não ao inimigo, para cada vitória sofreremos uma derrota. Se não nos conhecemos nem ao inimigo, sucumbiremos em todas as batalhas" ${ }^{\prime 3}$.

\section{A contra-inteligência}

Basicamente, a Contra-Inteligência é definida como uma atividade de informação que engloba um conjunto de medidas destinadas a 
neutralizar a eficiência dos serviços de informações adversos e a salvaguardar os segredos de interesse nacional.

A Contra-Inteligência e suas medidas são necessárias aos órgãos de informações e a qualquer entidade governamental ou privada que, por algum motivo, trabalhem com assuntos sigilosos ou equipamentos e materiais de interesse da segurança nacional.

Essa vertente da Inteligência tem uma preocupação constante no que se refere à segurança do desempenho das ações, dos documentos, dos materiais, do pessoal, das instalações e dos assuntos governamentais de caráter sigiloso. Essencialmente, em seu sentido mais amplo, a ContraInteligência é desenvolvida no interior do País, mas isso não implica que não haja atividade de Contra-Inteligência realizada no exterior.

Da mesma forma que se faz necessária a obtenção de conhecimentos para melhor fundamentar o processo decisório acerca de ameaças potenciais e reais para o Estado e fornecer subsídios que identifiquem oportunidades para que se alcancem os objetivos dos interesses nacionais, é de suma importância que os conhecimentos sensíveis, produzidos no País, sejam protegidos.

Conhecimento sensível é toda informação geradora de poder e cobiçada por terceiros (indivíduos, organizações e outros Estados) que possa trazer impactos para a segurança ou para a economia do Estado e que, por sua natureza, necessita de medidas especiais de proteção, tendo em vista a sua importância estratégica para as instituições nacionais e para o desenvolvimento do país. É um ativo cada vez mais precioso, pois gera desenvolvimento, e este acaba por atrair a atenção e o interesse de outros países.

Uma definição que pode ajudar a esclarecer a complexidade dessa área é: 
Em seus termos mais genéricos, a Contra-Inteligência se refere às informações coletadas e analisadas, e às atividades desenvolvidas, no sentido de proteger a nação (incluindo as suas próprias atividades relacionadas com a Inteligência) contra as ações de serviços de Inteligência hostis. Sob o manto desta definição, o âmbito da Contra-Inteligência é tão vasto quanto o âmbito da própria Inteligência em si, uma vez que é necessário se defender contra todas as formas de atividades de Inteligência hostis. ${ }^{14}$

Em seu livro intitulado "Da Guerra”, von Clausewitz esclarece que a defesa é a forma mais forte na guerra. A primeira linha de defesa de um Estado, anterior mesmo ao poderio bélico disponível, reside nos órgãos nacionais responsáveis pela Inteligência e Contra-Inteligência, pois eles são encarregados de cuidar da integridade do patrimônio intelectual nacional e das conquistas a ele ligadas. Conseguindo operar com êxito os vetores de busca de informações para ações preventivas, o desgaste com operações voltadas para a reação é minimizado, o que proporciona uma sempre desejável economia de recursos.

As atividades de Contra-Inteligência compreendem medidas passivas e ativas, podendo ser utilizadas como instrumento preventivo, atuando na proteção ao conhecimento, e como instrumento pró-ativo, executando ações de Contra-Espionagem.

As medidas passivas buscam impedir a obtenção de informações relativas às atividades desenvolvidas no país, em especial as que se relacionam com a segurança nacional. Tais medidas abrangem proteção, sigilo, dissimulação, controle e segurança do pessoal, do material e das áreas envolvidas nessas atividades; já as medidas ativas visam a reprimir, a reduzir ou a neutralizar ações adversas aos interesses nacionais, que interferem na conquista e na manutenção dos objetivos nacionais. 
Os métodos e técnicas utilizadas pela atividade de ContraInteligência são essencialmente semelhantes aos usados no ramo Inteligência. Entretanto, em virtude de sua finalidade operacional, suas ações costumam ocorrer em um prazo mais imediato ${ }^{15}$. Isso porque essa atividade se contrapõe às tentativas de acesso a informações que, em nome do interesse e da preservação da soberania da nação, devem ser mantidas em sigilo.

Uma das medidas ativas dentro do campo da ContraInteligência é o uso de uma técnica conhecida como desinformação, que consiste em mesclar informações verdadeiras com informações falsas, com o intuito de induzir a estratégia adversária a erros de julgamento, obstruindo ou, até mesmo, impedindo, desse modo, as possibilidades de êxito em tentativas de obtenção não-autorizada de informação sensível. Essa técnica deve ser elaborada de forma meticulosa, por possuir um alto grau de complexidade em sua estruturação. Deve-se evitar o uso excessivo de informações falsas, para que o alvo da desinformação não venha a desconfiar de sua suposta autenticidade, e procurar, também, manter um nível de fluxo de informações razoavelmente dentro da capacidade de assimilação do alvo, garantindo que as informações falsas sejam processadas e obtenham o resultado desejado. Por isso, a desinformação e a própria Contra-Inteligência possuem a virtude de fazer com que o adversário seja derrotado antes mesmo de perceber que está envolvido em um conflito.

Iludir os oponentes com essa e outras ações é necessário quando o que está em jogo é a preservação da soberania do Estado. O valor moral de tais ações fundamenta-se na segurança da pátria.

\section{A busca llícita}


Como dito anteriormente, o conhecimento é um bem cada vez mais precioso, um ativo estratégico fundamental e elemento-chave para a obtenção de vantagens competitivas sustentáveis dentro do permanente estado de conflito na arena internacional, onde interesses diferenciados levam a políticas divergentes - e conflitantes. E, justamente dentro desse contexto de conflito de interesses, uma vez que "as relações internacionais acontecem numa arena sem autoridade central para arbitrar os conflitos de interesses e os valores entre os Estados”"16, os atores internacionais identificam a necessidade de tomar conhecimento das capacidades e das intenções de grupos oponentes, os quais, logicamente, buscam manter a salvo da curiosidade alheia os conhecimentos considerados sensíveis.

$\mathrm{Na}$ arena internacional, é essencial para um país recolher e explorar de maneira sistemática as informações a respeito da conjuntura internacional, buscando informações referentes aos diferentes aspectos de outros países. Os itens de interesse abrangem condições políticas, econômicas, industriais, geográficas, psicossociais e militares, entre outros. Essas informações serão a base do processo de tomada de decisões no que concerne às políticas nacionais, servindo de subsídios para as esferas diplomática, militar, científica e econômica.

Por vezes, a tentativa de obtenção de conhecimentos de acesso negado ou protegido não se manifesta de maneira lícita, dado que "os interesses de Estado justificam o uso de meios externos que pareceriam repugnantes dentro de uma política doméstica bem ordenada” ${ }^{„ 17}$. Grupos adversos podem lançar mão de ações, visando à obtenção de dados e/ou conhecimentos que se encontram sob medidas de proteção, e esse tipo de ação ilícita à busca por conhecimentos sensíveis é caracterizado como espionagem. 
Como elucidado pelo Almirante Pierre Lacoste:

A justificação da função de espionagem é atestada na História pois a espionagem é tão velha quanto a guerra. É um fator chave na arte militar, citado nos mais antigos ataques de estratégia. Em todas as culturas guerreiras, os estratagemas, as astúcias utilizadas pelos agentes secretos fazem parte da herança e das tradições. A discrição, até mesmo o segredo mais rigoroso, se impõe nos negócios entre as grandes potências; a diplomacia não se faz na praça pública. Os múltiplos aspectos militares, políticos, culturais ou psicológicos relativos a idéia da clandestinidade testemunham a complexidade dos problemas ligados ao segredo de Estado nas sociedades contemporâneas. ${ }^{18}$

“Quando é negado o acesso a conhecimento importante e desejado, são usados todos os meios disponíveis, dos quais o principal continua a ser o primitivo espião, infiltrado ou recrutado entre os que podem ter acesso ao conhecimento necessário”19.

A espionagem pode ser entendida como sendo uma "ação realizada por pessoal vinculado ou não a serviço de Inteligência estrangeiro, que visa a obtenção de conhecimentos ou dados sigilosos os quais a um Estado interesse preservar"20.

Não obstante, informações particularmente importantes são mantidas sob sigilo. Portanto, para contornar essa proteção, ações de espionagem são executadas, tendo por objetivo acessar tais dados negados, buscando não somente conhecer as capacidades de países ou organizações adversas, mas, mais importante que isso, as intenções que movem seus governantes. 
Conquanto a linha de ação de um elemento opositor compreenda uma ampla combinação de fatores complexos e interdependentes, incluindo capacidades e planejamentos, para entendê-la, é necessário saber exatamente - ou da forma mais acurada possível - o que esse elemento opositor fará ou pretende fazer para alcançar uma vantagem competitiva. Desse modo, será possível identificar e estabelecer medidas e contramedidas para melhor lidar com qualquer cenário que venha a ser formulado. Por isso, a espionagem tem um caráter permanente, já que seu objetivo jamais cessa.

Os objetivos mais comuns da espionagem dizem respeito aos segredos militares, segredos de outros países ou informações relativas tanto à estabilidade quanto aos riscos aos quais outros governos estão expostos. De igual forma, são buscadas informações relativas à política externa, à situação econômica, ao comércio exterior ou a novas tecnologias desenvolvidas no país ou na área de interesse. Mas, atualmente, a forma mais comum é a espionagem econômica, que pode ser entendida como um amálgama de todas as outras formas.

O Coronel Gelio Fregapani explica:

entre os objetivos de qualquer nação estará o desenvolvimento econômico-industrial, e ela terá não só que sobrepujar os concorrentes como evitar ser sobrepujada. A espionagem lhe permite avaliar o poderio do concorrente, bem como beneficiar-se, com poucos gastos, dos progressos científicos dele (...) As mais diversas empresas e mesmo as nações procuram, por todos os meios, livrar-se dos custos de uma longa e incerta pesquisa e, principalmente, não serem superadas pelas concorrentes ou rivais. A espionagem econômica/comercial avulta na atualidade. $\mathrm{Na}$ verdade, nada há de novo na espionagem comercial/científica/industrial, ela sempre existiu, só que agora tomou um vulto maior, particularmente no 
campo da tecnologia nuclear e da ciência da computação. ${ }^{21}$

Diante do exposto, é possível notar a imprescindibilidade inerente à atividade de Inteligência. Além de ser um instrumento de poder do Estado com a missão de reconhecer oportunidades e ameaças relativas aos seus objetivos no contexto das relações internacionais, ela preza, em última análise, pela própria manutenção da ordem de um país. De igual forma, colabora, substantivamente, para o seu progresso, em prol da projeção do Poder Nacional, entendido este como sendo "a expressão integrada dos meios de toda ordem de que a Nação dispõe, efetivamente, para promover, no âmbito interno e no campo internacional, a consecução e salvaguarda dos objetivos nacionais, a despeito dos antagonismos internos e externos, existentes ou presumíveis”22.

${ }^{1}$ Parlamento Europeu: Relatório sobre a existência de um sistema global de interceptação de comunicações privadas e econômicas (sistema de interceptação Echelon).

${ }^{2}$ Frase dita por Claudianus (365-408 a.C.). Informação disponível em: $<$ www.chem.leeds.ac.uk>. Acesso em: 01/07/2004.

${ }^{3}$ BERNHARDT, D. "Strategic Intelligence: 'the Sword and the Shield' of the Enterprise”. Competitive Intelligence Magazine, v. 5, n. 5, p. 24-28, set./out. 2002. Tradução: "Você não pode proteger um Estado com sorrisos e apertos de mãos”. Tradução do autor.

${ }^{4}$ KENT, Sherman. Informações estratégicas. Rio de Janeiro: Biblioteca do Exército Editora, 1967.

${ }^{5}$ Agência Brasileira de Inteligência. Salvaguarda de assuntos sigilosos Proteção ao conhecimento: legislação vigente. Brasília: Abin, 2004. Série Coletânea de Legislação ${ }^{\circ} 4$.

6 Seminário Atividades de Inteligência no Brasil: Contribuições para a Soberania e a Democracia. Câmara dos Deputados, 2002.

${ }^{7}$ Citado no Seminário Atividades de Inteligência no Brasil: Contribuições para a Soberania e a Democracia. Câmara dos Deputados, 2002.

${ }^{8}$ A contribuição da Inteligência militar para a defesa nacional não se resume somente às operações militares per si, pois, também, "[the] planning requires a comprehensive analysis of the geopolitical and socioeconomic situation in the operational area and [in the] area of interest to ensure all factors 
affecting mission success are considered." - "planejamento requer uma ampla análise da situação geopolítica e socioeconômica da área operacional e da área de interesse para garantir que todos os fatores que afetam o sucesso da missão sejam considerados” (Tradução do autor)..Joint Chiefs of Staff: Doctrine for Joint Special Operations - Joint Publication 3-05 (2003:IV-1).

${ }^{9}$ OLIVEIRA, Lúcio Sérgio Porto. A história da atividade de Inteligência no Brasil. Brasília: Abin, 1999.

10 "A tomada de decisões apóia-se fundamentalmente nas informações disponíveis sobre um problema considerado, de maneira a propiciar ao usuário razoável número de alternativas, uma das quais, escolhida como a melhor ou mais favorável, caracteriza o ato decisório". Escola Superior de Guerra: Manual Básico.

${ }^{11}$ Escola Superior de Guerra: Manual Básico.

12 Clausewitz esclarece que "o termo 'informação' designa o conjunto de conhecimentos relativos ao inimigo e ao seu país e, por conseqüência, a base sobre a qual se fundamentam as nossas próprias idéias e os nossos atos". CLAUSEWITZ, Carl von. Da Guerra. $2^{\mathrm{a}}$ edição. São Paulo: Martins Fontes, 1996.

${ }^{13}$ TZU, Sun. A arte da guerra. Tradução José Sanz. 14a edição. Rio de Janeiro: Record, 1993.

${ }^{14}$ Escola Superior de Guerra: Manual Básico.

15 “Além disso, em razão da diversidade dos meios, lugares e focos das ações de espionagem, as medidas de neutralização devem ser planejadas e executadas de modo a atender especificamente cada situação. Esses fatores acrescem à tarefa da contra-espionagem maior grau de sensibilidade e temporalidades, por vezes, imprevisíveis”. Agência Brasileira de Inteligência. Relatório anual Abin 2002. Brasília: Abin, 2002.

16 GRIFFITHS, Martin. 50 grandes estrategistas das Relações Internacionais. Tradução Vânia de Castro. São Paulo: Contexto, 2004.

${ }^{17}$ Idem.

${ }^{18}$ LACOSTE, P. Conferência na Academia de Ciências Morais, Paris, em 05/02/1996.

${ }^{19}$ FREGAPANI, Gelio. Segredos da espionagem - a influência dos serviços secretos nas decisões estratégicas. Brasília: Thesaurus, 2001.

${ }^{20}$ Agência Brasileira de Inteligência. A Inteligência em defesa da sociedade, do Estado democrático de Direito e dos interesses nacionais. Brasília: Abin, 2002

${ }^{21}$ FREGAPANI, Gelio. Segredos da espionagem - a influência dos serviços secretos nas decisões estratégicas. Brasília: Thesaurus, 2001.

${ }^{22}$ SILVA, General Golbery do Couto e. Conjuntura política nacional - O Poder Executivo \& Geopolítica do Brasil. $3^{\text {a }}$ edição. Rio de Janeiro: J. Olympio Editora, 1981.

\section{Intelligence Activities and International Relations}




\begin{abstract}
Within the sphere of interests of International Relations, governments are constantly on the lookout for that most precious of all needs: knowledge, the driving force of development and coated with strategic importance. Progress achieved by one country will of necessity arouse the interest of other countries, who in the race for competitive advantage will use whatever means, fair of foul to obtain access to strategic information kept under lock and key, and subject to the machinations of espionage. To keep such information under tight security control, governments depend on their Intelligence services, whose function is to identify threats and loop-holes in the turbulent international scenario.
\end{abstract}

Keywords: International relations. Intelligence. Strategic knowledge.

\title{
Referências
}

AGÊNCIA BRASILEIRA DE INTELIGÊNCIA. A Inteligência em defesa da sociedade, do Estado democrático de Direito e dos interesses nacionais. Brasília: Abin, 2002

Relatório anual Abin 2002. Brasília: Abin, 2002.

- Salvaguarda de assuntos sigilosos: proteção ao conhecimento, legislação vigente. Brasília: Abin, 2004. (Série Coletânea de Legislação, 4)

BERNHARDT, D. Strategic Intelligence: the Sword and the Shield of the Enterprise. Competitive Intelligence Magazine, v. 5, n. 5, p. 24-28, set./out. 2002.

CLAUSEWITZ, Carl Von. Da Guerra. 2 ed. São Paulo: Martins Fontes, 1996.

FREGAPANI, Gelio. Segredos da espionagem: a influência dos serviços secretos nas decisões estratégicas. Brasília: Thesaurus, 2001.

GRIFFITHS, Martin. 50 grandes estrategistas das Relações Internacionais. Tradução Vânia de Castro. São Paulo: Contexto, 2004. 
Joint chiefs of staff: doctrine for joint special operations - Joint Publication, v. 4, n.1, p. 3-5, 2003.

KENT, Sherman. Informações estratégicas. Rio de Janeiro: Biblioteca do Exército, 1967.

CONFERÊNCIA NA ACADEMIA DE CIÊNCIAS MORAIS, nº 1996 Paris.

OLIVEIRA, Lúcio Sérgio Porto. A história da atividade de inteligência no Brasil. Brasília: Abin, 1999.

ATIVIDADES de inteligência no Brasil: contribuições para a soberania e a democracia. In: SEMINÁRIO, 2002, Câmara dos Deputados, 2002

SILVA, Golbery do Couto e. Conjuntura política nacional: o poder executivo e geopolítica do Brasil. 3. ed. Rio de Janeiro: J. Olympio, 1981.

TZU, Sun. A arte da guerra. Tradução José Sanz. 14. ed. Rio de Janeiro: Record, 1993. 